\title{
Oral kallidinogenase improved visual acuity and maintained chorioretinal blood flow levels after treatment for diabetic macular edema
}

This article was published in the following Dove Press journal:

Clinical Ophthalmology

\author{
Eiko Tsuiki' \\ Kiyoshi Suzuma ${ }^{2}$ \\ Makiko Matsumoto' \\ Yasser Helmy Mohamed' \\ Takashi Kitaoka' \\ 'Department of Ophthalmology \\ and Visual Sciences, Graduate \\ School of Biomedical Sciences, \\ Nagasaki University, Nagasaki, Japan; \\ ${ }^{2}$ Department of Ophthalmology and \\ Visual Sciences, Kyoto University \\ Graduate School of Medicine, \\ Kyoto, Japan
}

Purpose: This study was designed to investigate the therapeutic effects of oral kallidinogenase medication as an adjuvant therapy in treating patients with diabetic macular edema (DME).

Study design: This was a prospective, open-labeled, randomized study.

Methods: All patients were given posterior sub-Tenon triamcinolone acetonide (STTA) injection and focal laser treatment session for DME. The patients were subdivided into two groups: 1) those treated with oral kallidinogenase for at least 6 months after local treatment (treated group) and 2) those treated without oral kallidinogenase (untreated group). In this study, best-corrected visual acuity (BCVA), central retinal thickness (CRT), subfoveal choroidal thickness (SCT), and chorioretinal blood flow level were measured in 17 patients (19 eyes). Chorioretinal blood flow levels at the disc and macula were measured by laser speckle flowgraphy and evaluated using the mean blur rate (MBR). These data were measured at baseline and at 1, 3, and 6 months after treatment initiation.

Results: BCVA at 6 months after treatment significantly improved in treated group $(P<0.05)$. But the mean CRT after treatment significantly decreased in both groups. There was no significant difference in the mean SCT at baseline between the two groups. The mean SCT after treatment in treated group was significantly thinner than that before treatment $(P<0.05)$. Compared to baseline (100\%), MBR at the disc and the macula at 6 months after treatment significantly decreased to $84.8 \%$ and $86.2 \%$, respectively, in untreated group $(P<0.05)$, though it remained unchanged at $98.7 \%$ and $99.7 \%$ in treated group.

Conclusion: Oral kallidinogenase medication is useful as an adjuvant therapy to enhance the therapeutic effect of STTA in DME patients.

Keywords: kallidinogenase, diabetic macular edema, laser speckle flowgraphy, enhanced depth imaging optical coherence tomography

\section{Introduction}

Diabetic macular edema (DME) is the leading cause of blindness in patients with diabetic retinopathy worldwide. ${ }^{1}$ The pathogenesis of DME has long been attributed to retinal vascular hyperpermeability, which is associated with focal leakage from microaneurysms or diffuse leakage from incompetent capillaries when visualized on fluorescein angiography (FA). Functional imaging studies also showed a reduction in choroidal blood flow in the eyes of patients with diabetic retinopathy. ${ }^{2}$ However, the role of choroidal perfusion in the pathophysiology of DME remains unclear. ${ }^{3}$ Early Treatment Diabetic Retinopathy Study applied focal laser photocoagulation to leakage from microaneurysms and grid laser photocoagulation to leakage from capillary areas. ${ }^{4}$ In addition, many reports have been made on the effectiveness of sub-Tenon
Department of Ophthalmology and Visual Sciences, Graduate School of Biomedical Sciences, Nagasaki University, I-7-I Sakamoto, Nagasaki 8528501 , Japan $\mathrm{Tel}+8 \mid 958197345$

Fax +81958197347

Email t-eiko@nagasaki-u.ac.jp 
triamcinolone acetonide (STTA) injection for the treatment of diffuse macular edema that is refractory to laser therapy. ${ }^{5,6}$ This study was proposed due to the possibility of treatment that further enhances these effects. Kallidinogenase acts on kininogen in plasma to liberate kinins, thereby exerting a peripheral vasodilating effect via the enhancement of nitrous oxide production. This process is believed to result in improved chorioretinal circulation and, in fact, certain reports have indicated that administration of this enzyme produces an increase in chorioretinal blood flow ${ }^{7-9}$ or results in an antivascular endothelial growth factor (VEGF) effect. ${ }^{10,11}$ Kallidinogenase is currently used in the treatment of patients with diabetic retinopathy or retinal vein occlusion in Japan. Recent studies of choroidal thickness in the eyes of patients with DME and proliferative diabetic retinopathy have produced diverging results, however, with some reports suggesting choroidal thickening, thinning, and no change in eyes with DME. ${ }^{12-15}$ Laser speckle flowgraphy (LSFG) allows for the quantitative estimation of blood flow changes in the optic nerve head, choroid, retina, and iris in vivo to make the same area measurable repeatedly in the same eye. It was developed to facilitate the noncontact analysis of ocular blood flow in living eyes, utilizing the laser speckle phenomenon. ${ }^{16-18}$ Our aims in this study were to investigate the therapeutic effects of oral kallidinogenase medication as an adjuvant therapy in treating patients with DME and to evaluate chorioretinal blood flow changes and choroidal thickness changes using LSFG and enhanced depth imaging optical coherence tomography (EDI-OCT) as a result of this treatment.

\section{Materials and methods Experimental design}

This was a prospective, single center, open-labeled, randomized clinical study carried out at the Department of Ophthalmology, Nagasaki University, Japan.

\section{Patients}

Patients with type 2 diabetes who had DME were eligible for this clinical trial. The criterion for thickening of the central macula was defined as a central retinal thickness (CRT) of $300 \mu \mathrm{m}$ in the central subfield. This study was conducted in 19 eyes of 17 consecutive patients. Snellen best-corrected baseline visual acuity (BCVA) was measured by a certified examiner for all patients. For baseline evaluation, all patients underwent slit-lamp examination, gonioscopy, intraocular pressure measurement with Goldmann tonometry, dilated fundus examination, FA, fundus photography, spectral domain optical coherence tomography (SD-OCT), LSFG, and blood pressure measurement before laser treatment. BCVA was expressed as the logarithm of the minimum angle of resolution ( $\log$ MAR). BCVA was recorded at the baseline examination and at every subsequent visit. The exclusion criteria were corneal opacity, cataract, and vitreous hemorrhage that could influence vision and digital photography, history of ocular hypertension or glaucoma of the study eye, any previous ocular condition that may be associated with a risk of macular edema due to age-related macular degeneration and choroidal neovascularization, planned intraocular surgery within 6 months, vitreomacular traction or epiretinal membrane on OCT scan, history of chronic renal failure or renal transplant for diabetic nephropathy, uncontrolled hypertension (180/100 mmHg), and any systemic medication that is known to be toxic to the retina or associated with a risk of macular edema. This study adhered to the principles of the Declaration of Helsinki and obtained approval from the Institutional Review Board (IRB) of the Nagasaki University to conduct this study. This study was registered with the University Hospital Medical Information Network - Clinical Trials Registry (UMIN-CTR) of Japan (ID UMIN000005339; date of access and registration, April 1, 2011). All participants provided written informed consent and the nature and possible consequences of the study were explained to them. All participants were given STTA and focal laser treatment session for DME and were subdivided into two groups using the assignment table for randomization. First group patients were treated with oral kallidinogenase for at least 6 months after local treatment (treated group), whereas the second group patients were treated without oral kallidinogenase (untreated group).

\section{Local treatment of DME STTA method}

Under local anesthesia with oxybuprocaine hydrochloride eye drops, a conjunctival incision was made at the inferotemporal quadrant. Tenon's incision was made midway between the inferior and lateral rectus muscles, about $7 \mathrm{~mm}$ posterior to the limbus, and the surface of the sclera was confirmed. A 25-gauge straight blunt cannula was inserted through the sub-Tenon space reaching the posterior pole and $20 \mathrm{mg}(0.5 \mathrm{~mL})$ of triamcinolone acetonide (Kenacort- ${ }^{\circledR}$; $40 \mathrm{mg} / \mathrm{mL}$ ) was injected.

\section{Focal laser method}

The focal photocoagulation was performed using the following parameters: wavelength $532 \mathrm{~nm}$, spot size $50-60 \mu \mathrm{m}$, laser power 70-100 mW, and pulse duration $100 \mathrm{~ms}$. The target was microaneurysms that were detected by FA. 


\section{Kallidinogenase medication}

Oral kallidinogenase (CARNACULIN ${ }^{\circledR}$ Tablet 50 units; Sanwa Kagaku Kenkyusho Co., Ltd., Nagoya, Japan) was administered to the treated group - a total of 150 units divided into 3 doses per day for 6 months.

\section{Measuring chorioretinal blood flow}

The principles of the LSFG technique, which are based upon and its applications in measuring blood flow of the optic disc, have been described in detail in the previous publications. ${ }^{16-18}$ The most recently available LSFG NAVI system (Softcare Co., Ltd., Fukutsu, Japan) uses a fundus camera that is equipped with a diode laser (wavelength, $830 \mathrm{~nm}$ ) and a highly sensitive charge-coupled device camera $(750 \times 360$ pixels). Images are acquired continuously at the rate of 30 frames per second and then averaged to produce a composite map of ocular blood flow. The primary measurement parameter of LSFG is mean blur rate (MBR), a measurement of the relative velocity of blood flow. The MBR displayed as a 2D color-coded map. Similarly, the LSFG provided the novel measurement parameter of the retinal vessel within or nearby the optic disc region. We determined the margin of the optic disc with a round rubber band. After circling the area around the optic disc, we then investigated the MBR of the major vessel (artery and vein) within this circle. Since the MBR in the vessel area (MV) includes the MBR in the tissue area (MT), the MBR used to evaluate the blood flow in the retinal vessel excluded the MT as choroidal blood flow (MV-MT) (Figure 1A). Also, we measured the choroidal blood flow at the macula by the following steps: First, we measured the MBR in the chorioretinal tissue at macular area, compared LSFG MBR maps with fundus photographs, configured isometric areas for analysis at macula, and then calculated the average blur rate in the whole area without separating vessels and tissues (Figure 1B). The parameters of MBR used in this study were calculated by the equipped software (LSFG Analyzer, version 3.0.39.0; Softcare Ltd.). We then saved the position of each region of interest in software, and reused it in subsequent analyses of the same patient. We recorded the MBR of the optic disc and the chorioretinal blood flow at the macula before and after 1, 3, and 6 months of local treatment in both groups and calculated the percentage according to the pretreatment value (100\%).

\section{OCT measurements}

CRT was measured by CIRRUSTM HD-CT (Carl Zeiss Meditec Inc., Dublin, CA, USA) using the macular cube 512×128 protocol. The subfoveal choroidal thickness (SCT) was measured by SPECTRALIS ${ }^{\text {TM }}$ SD-OCT (Heidelberg Engineering $\mathrm{GmbH}$, Heidelberg, Germany) according to the EDI-OCT technique described by Spaide et al. ${ }^{19}$ The choroidal thickness was measured vertically from the outer border of the hyperreflective line corresponding to the retinal pigment epithelium (RPE) to the inner border of the sclera. Choroidal thickness
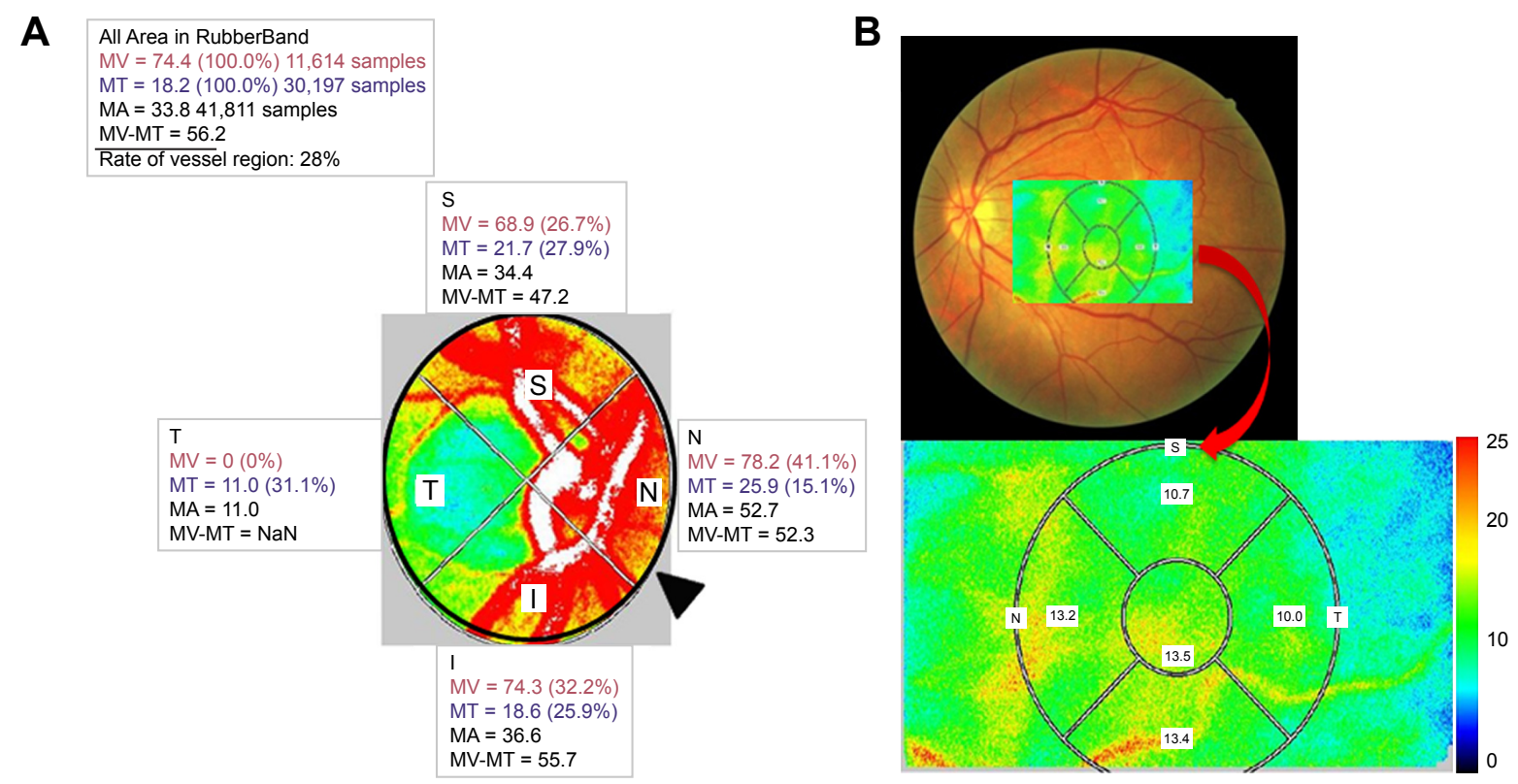

Figure I The mean blur rate (MBR) displayed as a 2D color-coded map. (A) MBR at the disc as the retinal blood flow, which was calculated automatically after circling the margin of the optic disc with a rubber band $(\mathbf{\Delta})$. Since the MBR in the vessel area $(M V)$ includes the MBR in the tissue area $(M T)$, the MBR $(M V-M T)$ was used as the retinal blood flow. (B) MBR at the macula which calculated automatically after configured isometric areas compared MBR maps with fundus photographs was used as the choroidal blood flow. 
measurements were made under the fovea. Both CRT and SCT were measured before and after 1, 3, and 6 months of local treatment of DME in both groups.

\section{Statistical analysis}

Statistical analyses with the significance of BCVA, CRT, $\mathrm{SCT}$, and MBR alterations were performed by repeated measures ANOVA followed by multiple comparisons Bonferroni tests. Group comparisons were made using unpaired $t$-test, $2 \times 2$ chi-square tests, and Fisher's test. $P<0.05$ was considered to be statistically significant.

\section{Results}

\section{Patient demographics}

The demographics of diabetic patients are shown in Table 1. Ten eyes were assigned to kallidinogenase-treated group and 9 eyes were assigned to untreated group. There were 6 eyes with intraocular lens (IOL) in the treated group. On the other hand, there were 2 eyes with IOL in the untreated group. There was no statistically significant difference at baseline. Table 2 also shows the mean BCVA, CRT, SCT, and MBR of both groups before and after 1, 3, and 6 months of local treatment. There was no statistically significant difference between the treated and untreated groups as regards BCVA, CRT, SCT, and MBR along the whole follow-up period except the MBR at the macula after 6 months of local treatment $(P<0.05)$.

\section{LogMAR BCVA}

The logMAR of BCVA was 0.15 at baseline in the untreated group and changed to $0.18,0.18$, and 0.20 after 1,3 , and 6 months of local treatment, respectively. However, the $\log$ MAR of BCVA was 0.20 at baseline in the treated group and changed to $0.18,0.13$, and 0.13 after 1,3 , and 6 months of local treatment, respectively. BCVA significantly improved in the treated group at 3 and 6 months from baseline $(P<0.05)$ and remained unchanged in the untreated group (Figure 2A).

\section{CRT measurements}

Initially, the CRT was $369.6 \mu \mathrm{m}$ at the baseline in the untreated group and reduced to $327.4,311.2$, and $310.7 \mu \mathrm{m}$ after 1,3 , and 6 months of local treatment, respectively. Similarly, the CRT was $395.2 \mu \mathrm{m}$ at the baseline in the treated group and reduced to $329.9,327.1$, and $341.2 \mu \mathrm{m}$ after 1,3 , and 6 months of local treatment, respectively. There was a statistically significant reduction as regards CRT during the whole follow-up period in both groups $(P<0.05)$ (Figure 2B).

\section{SCT measurements}

Initially, SCT was $292.1 \mu \mathrm{m}$ at the baseline in the untreated group and reduced to 281.7, 288.4, and $293.9 \mu \mathrm{m}$ after 1, 3, and 6 months of local treatment, respectively. There was statistically significant reduction as regards SCT after 1 month of follow-up in untreated group $(P<0.05)$ (Figure 2C). Similarly, SCT was $298.1 \mu \mathrm{m}$ at the baseline in the treated group and reduced to $269.8,283.7$, and $287.1 \mu \mathrm{m}$ after 1,3 , and 6 months of local treatment, respectively. There was statistically significant reduction as regards SCT along the whole follow-up period in the treated group $(P<0.05)$ (Figure $2 \mathrm{C})$.

\section{Change in retinal blood flow (MBR at the disc) and choroidal blood flow (MBR at the macula)}

Retinal blood flow decreased in the untreated group with statistically significant reduction after 3 and 6 months of follow-up of local treatment $(P<0.05)$ (Figure 3A). In contrast, the retinal blood flow remained unchanged in the treated group with no significant change along the whole follow-up period (Figure 3A). Although the choroidal blood flow decreased in the untreated group with statistically significant reduction after 6 months of follow-up of local treatment $(P<0.05)$, it remained unchanged in the treated group with no significant change along the follow-up period (Figure 3B) after 6 months of local treatment a significant difference of $(P<0.05)$ was found between the two groups with regard to choroidal blood flow. Furthermore, there was a significant negative correlation between BCVA and retinal blood flow (MBR at the disc) in the treated group at 6 months (Figure 4).

\section{Discussion}

In this prospective study, oral kallidinogenase medication as an adjuvant therapy had a significant effect on functional

Table I Demographics of patients with diabetic macular edema

\begin{tabular}{llll}
\hline & Kallidinogenase $(+)$ & Kallidinogenase (-) & $P$-value \\
\hline Number of eyes & 10 & 9 & - \\
Mean age \pm SD (years) & $62.1 \pm 4.91$ & $62.4 \pm 0.46$ & 0.46 \\
Sex (male/female) & $7 / 3$ & $5 / 4$ & 0.23 \\
Lens (cataract//OL) & $4 / 6$ & $7 / 2$ & 0.17 \\
\hline
\end{tabular}

Abbreviation: IOL, intraocular lens. 
Table 2 Changes in visual parameters over time

\begin{tabular}{|c|c|c|c|c|c|c|c|c|}
\hline & Baseline & & I month & & 3 months & & 6 months & \\
\hline Kallidinogenase & + & - & + & - & + & - & + & - \\
\hline $\mathrm{BCVA} \pm \mathrm{SD}(\log M A R)$ & $0.20 \pm 0.11$ & $0.15 \pm 0.11$ & $0.18 \pm 0.11$ & $0.17 \pm 0.15$ & $0.13 \pm 0.13$ & $0.18 \pm 0.14$ & $0.13 \pm 0.13$ & $0.20 \pm 0.15$ \\
\hline $\mathrm{CRT} \pm \mathrm{SD}(\mu \mathrm{m})$ & $395.2 \pm 89.8$ & $369.6 \pm 67.4$ & $329.9 \pm 72.0$ & $327.4 \pm 34.9$ & $327.1 \pm 76.2$ & $311.2 \pm 39.0$ & $341.2 \pm 126.9$ & $310.7 \pm 44.7$ \\
\hline $\mathrm{SCT} \pm \mathrm{SD}(\mu \mathrm{m})$ & $298.1 \pm 75.0$ & $292.1 \pm 101.6$ & $269.8 \pm 68.1$ & $281.7 \pm 106.0$ & $283.7 \pm 75.7$ & $288.4 \pm 102.6$ & $287.1 \pm 75.3$ & $293.9 \pm 94.7$ \\
\hline \multicolumn{9}{|l|}{ Blood flow (MBR) } \\
\hline Retina (disc; \%) & 100 & 100 & 87.2 & 93.2 & 91.8 & 87.9 & 98.7 & 84.8 \\
\hline Choroid (macula; \%) & 100 & 100 & 96.4 & 93.7 & 95.7 & 90.8 & $99.7^{\dagger}$ & $86.2^{*}$ \\
\hline
\end{tabular}

Notes: *Unpaired $t$-test; $P<0.05$.

Abbreviations: BCVA, best-corrected visual acuity; CRT, central retinal thickness; SCT, subfoveal choroidal thickness; MBR, mean blur rate; logMAR, logarithm of the minimum angle of resolution.

resolution after treatment for DME. Among the risk factors for diabetic retinopathy, VEGF is the predominant cytokine that accelerates vascular permeability and endothelial cell growth. ${ }^{20}$ The VEGF levels in the vitreous and aqueous humors of patients with diabetic retinopathy or DME were higher than that in patients without diabetic retinopathy or DME. ${ }^{21-23}$ Funatsu et al also reported that the VEGF level was related to the retinal thickness at the central fovea. ${ }^{21}$ These results indicate that improved vascular permeability and decreased concentrations of VEGF in diabetes are crucial to stop the development of retinopathy and DME.

Recently, it has been reported that kallidinogenase normalizes retinal vasopermeability ${ }^{8}$ and inhibits retinal and choroidal neovascularizations via the cleavage of VEGF165 or VEGF 164. ${ }^{9-11}$ Furthermore, it was reported that tissue kallikrein administered intravenously normalizes retinal vasopermeability via suppression of the intraocular VEGF level in streptozotocin-induced diabetic rats. ${ }^{8}$ Kallidinogenase, also known as kallikrein, is derived from blood plasma or tissue and has a serine protease that is capable of cleaving kininogen to release vasoactive kinins. ${ }^{24}$ These kinins activate bradykinin B2 receptors and cause a peripheral vasodilating effect via the enhancement of nitrous oxide production. This process is believed to result in improved chorioretinal circulation. ${ }^{7}$ From these evidence, it can be concluded that the suppressive effect of kallidinogenase on

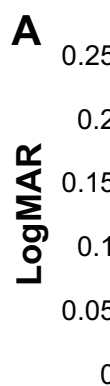

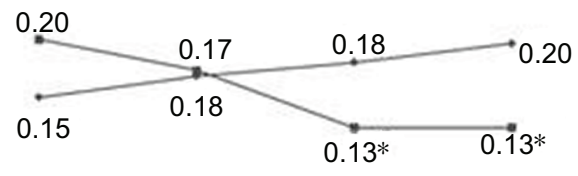
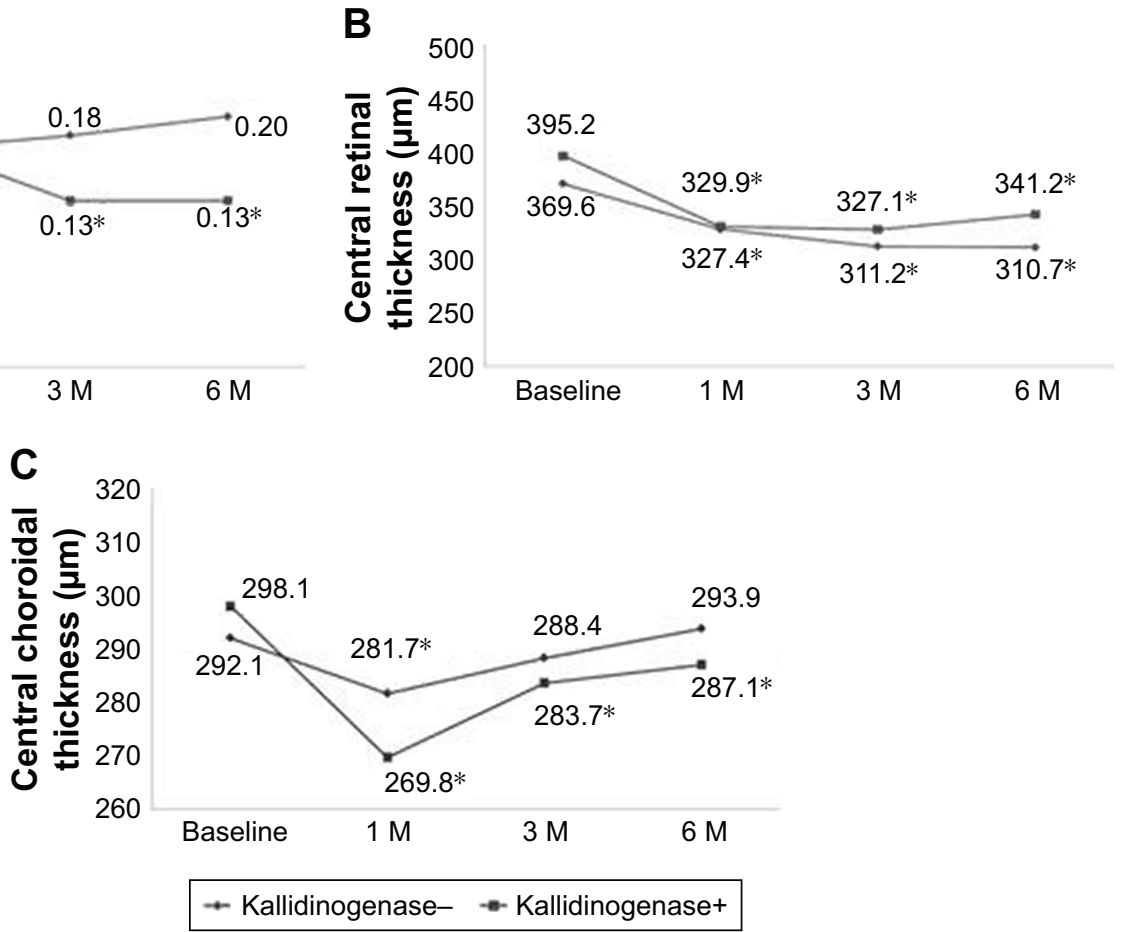

Figure 2 (A) Change in the best-corrected visual acuity (BCVA). BCVA was significantly improved in the treated group at 3 and 6 months from baseline $(* P<0.05)$ and remained unchanged in the untreated group. (B) Change in the central retinal thickness (CRT). CRT was significantly improved during the whole follow-up period in both groups $\left({ }^{*} P<0.05\right)$. There was no significant difference between the two groups. (C) Change in the subfoveal choroidal thickness $(\mathrm{SCT})$. SCT was significantly reduced during the whole follow-up period in the treated group $(* P<0.05)$. On the other hand, SCT was significantly reduced only at I month from baseline in the untreated group $(* P<0.05)$. 


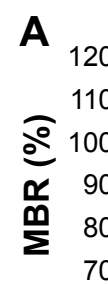

60
100

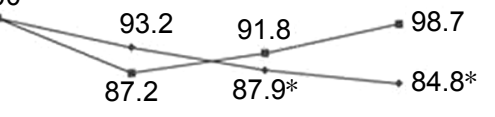

Baseline $\quad 1 \mathrm{M}$
B

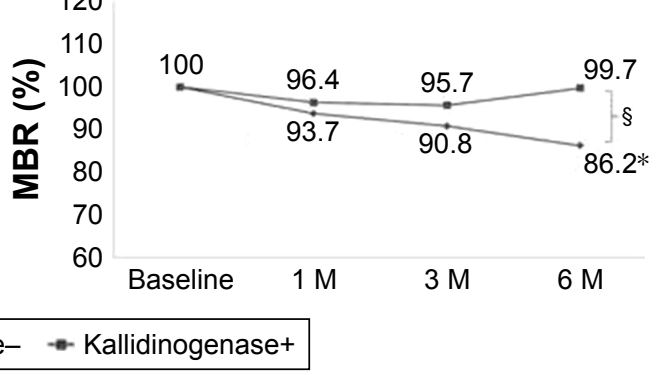

Figure 3 (A) Change in the mean blur rate (MBR) at the disc as the retinal blood flow. Although the retinal blood flow significantly decreased in the untreated group at 3 and 6 months from baseline $(* P<0.05)$, it remained unchanged during the whole follow-up period in the treated group. (B) Change in MBR at the macula as the choroidal blood flow. Although the choroidal blood flow significantly decreased in the untreated group at 6 months from baseline $(* P<0.05)$, it remained unchanged during the whole follow-up period in the treated group. There was a significant difference between the two groups after 6 months $(\$ P<0.05)$.

increased retinal vascular permeability can be attributed to a vascular protective effect resulting from the activation of the bradykinin-nitrous oxide system in addition to a VEGFsuppressing effect.

In our study, we confirmed that BCVA was significantly improved in the treated group and remained unchanged in the untreated group, whereas CRT was significantly improved in both groups. This means that oral kallidinogenase medication had not only morphological improvement but also functional improvement as an adjuvant therapy for DME. Since EDI-OCT allows the clinical evaluation of choroidal changes noninvasively, ${ }^{19}$ studies addressing choroidal thickness have been conducted for various retinal diseases. ${ }^{25-27}$ Choroidal ischemia may also play a role in the VEGF-driven response resulting in DME. ${ }^{25}$ Therefore, by blocking the action of VEGF on the choroid with kallidinogenase therapy, the permeability of the choroidal vasculature decreases, which can be noted by a decrease in choroidal thickness. Sonoda et al reported that SCT of DME eyes was significantly reduced from the baseline by intravitreal

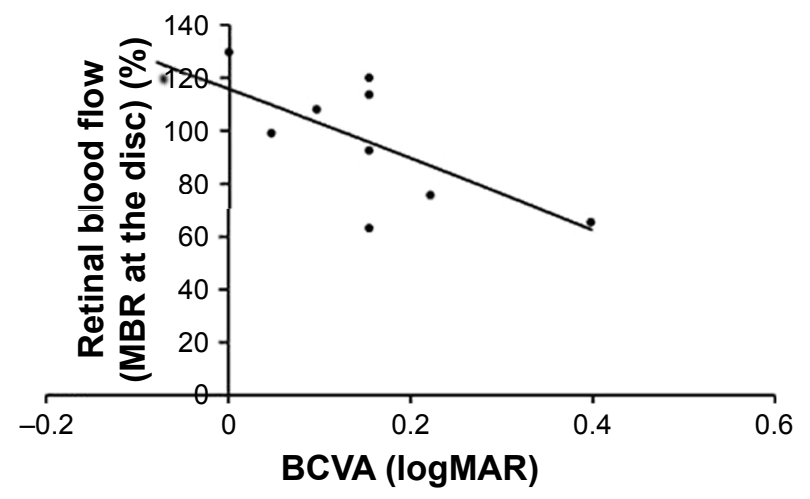

Figure 4 Spearman's correlation between the mean blur rate (MBR) at the disc and the best-corrected visual acuity (BCVA). Significant negative correlation between $B C V A$ and retinal blood flow was noted in the treated group at 6 months $(P=0.01)$. triamcinolone acetonide or bevacizumab and suggested that the choroidal pathology in diabetic retinopathy might be due to steroid-sensitive factors rather than VEGF. ${ }^{28}$ In this study, we confirmed significant reduction in SCT in the treated group throughout the follow-up period and only in the first month in the untreated group. Although the decrease in choroidal thickness is not associated with visual or anatomic outcomes, this sustainable reduction especially in the treated group suggests that oral kallidinogenase medication can extend the effects of STTA. The choroid contributes to the metabolic support of RPE and compromised choroidal blood flow can result in photoreceptor dysfunction and death with visual disability. Nagaoka et al reported that choroidal blood flow in patients with type 2 diabetes significantly decreased, especially in those with DME. ${ }^{2}$ In our study, we also noted that although the retinal and choroidal blood flow significantly decreased in the kallidinogenase untreated group, they remained unchanged in the treated group. This means that the treated group had relative increase in both retinal and choroidal blood flow compared to the untreated group. Therefore, we suggest that chorioretinal blood flow and its enhancement are more important than the changes in choroidal thickness. In this study, we confirmed that there was a statistical difference between the two groups after 6 months of follow-up as regards to choroidal blood flow, and significant negative correlation between BCVA and retinal blood flow was noted in the treated group at 6 months. LSFG allows for noninvasive quantification of the microcirculation in the optic disc, choroid, and retinal vessels separately in living eyes. ${ }^{16-18}$ LSFG method is therefore suitable for monitoring the time course of changes in tissue circulation at the same site in the same eye at various intervals, ranging from seconds to months. ${ }^{29,30}$ There are limitations to this prospective study. The number of the patients was small and 
kallidinogenase is not used for ocular diseases in the West. Further studies targeting more patients or combinations with anti-VEGF therapy are considered to be necessary.

\section{Conclusion}

We conclude that kallidinogenase is able to improve chorioretinal blood flow levels in DME patients, and this improvement was associated with the improvement in BCVA. In addition, the measurement of retinal blood flow by LSFG is potentially useful as a prognostic factor for BCVA and oral kallidinogenase medication is useful as an adjuvant therapy to enhance the therapeutic effect of STTA in DME patients. This study may be a novel contribution in the investigation of new possible therapies for the treatment of DME.

\section{Disclosure}

The authors report no conflicts of interest in this work.

\section{References}

1. Antonetti DA, Barber AJ, Bronson SK, et al. Diabetic retinopathy: seeing beyond glucose-induced microvascular disease. Diabetes. 2006; 55:2401-2411.

2. Nagaoka T, Kitaya N, Sugawara R, et al. Alteration of choroidal circulation in the foveal region in patients with type 2 diabetes. $\mathrm{Br} J$ Ophthalmol. 2004;88:1060-1063.

3. Hidayat A, Fine B. Diabetic choroidopathy: light and electron microscopic observations of seven cases. Ophthalmology. 1985;67: $512-522$.

4. Early Treatment Diabetic Retinopathy Study Research Group. Photocoagulation for diabetic macular edema. Early Treatment Diabetic Retinopathy Study report number 1. Arch Ophthalmol. 1985;103: 1796-1806.

5. Koga T, Mawatari Y, Inumaru J, Fukushima M, Tanihara H. Trans-Tenon's retrobulbar triamcinolone acetonide infusion for refractory diabetic macular edema after vitrectomy. Graefes Arch Clin Exp Ophthalmol. 2005;243:1247-1252.

6. Wada M, Ogata N, Minamino K, Koriyama M, Higuchi A, Matsumura M. Trans-Tenon's retrobulbar injection of triamcinolone acetonide for diffuse diabetic macular edema. Jpn J Ophthalmol. 2005;49: 509-515.

7. Yamaguchi T, Nagano H, Yamaguchi M, Suzuki T, Saito Y, Tano Y. The effects of kallidinogenase on choroidal blood flow in a hypertensive rabbit model. Curr Eye Res. 1999;18:417-422.

8. Kato N, Hou Y, Lu Z, et al. Kallidinogenase normalizes retinal vasopermeability in streptozotocin-induced diabetic rats: potential roles of vascular endothelial growth factor and nitric oxide. Eur J Pharmacol. 2009;606:187-190.

9. Fukaya Y, Tamaki Y, Tomidokoro A, Araie M. Effects of kallidinogenase on ocular tissue circulation in rabbits. $J$ Ocul Pharmacol Ther. $2002 ; 18: 515-524$.

10. Nakamura S, Morimoto N, Tsuruma K, et al. Tissue kallikrein inhibits retinal neovascularization via the cleavage of vascular endothelial growth factor-165. Arterioscler Thromb Vasc Biol. 2011;31:1041-1048.

11. Fukubara J, Noda K, Murata M, et al. Tissue kallikrein attenuates choroidal neovascularization via cleavage of vascular endothelial growth factor. Invest Ophthalmol Vis Sci. 2013;54:274-279.
12. Querques G, Lattanzio R, Querques L, et al. Enhanced depth imaging optical coherence tomography in type 2 diabetes. Invest Ophthalmol Vis Sci. 2012;53:6017-6024.

13. Lains I, Figueira J, Santos AR, et al. Choroidal thickness in diabetic retinopathy: the influence of antianiogenic therapy. Retina. 2014;34: 1199-1207.

14. Kim JT, Lee DH, Joe SG, Kim JG, Yoon YH. Changes in choroidal thickness in relation to the severity of retinopathy and macular edema in type 2 diabetic patients. Invest Ophthalmol Vis Sci. 2013;54: $3378-3384$.

15. Regatieri CV, Branchini L, Carmody J, Fujimoto JG, Duker JS. Choroidal thickness in patients with diabetic retinopathy analyzed by spectral-domain optical coherence tomography. Retina. 2012;32: 563-568.

16. Tamaki Y, Araie M, Kawamoto E, Eguchi S, Fujii H. Non-contact, two-dimensional measurement of tissue circulation in choroid and optic nerve head using laser speckle phenomenon. Exp Eye Res. 1995;60: 373-383.

17. Sugiyama T, Araie M, Riva CE, Schmetterer L, Orgul S. Use of laser speckle flowgraphy in ocular blood flow research. Acta Ophthalmol. 2010;88:723-729.

18. Ubuka M, Sugiyama T, Onoda Y, Shiba T, Hori Y, Maeno T. Changes in the blood flow of the optic nerve head induced by different concentrations of epinephrine in intravitreal infusion during vitreous surgery. Invest Ophthalmol Vis Sci. 2014;55:1625-1629.

19. Spaide RF, Koizumi H, Pozzoni MC. Enhanced depth imaging spectraldomain optical coherence tomography. Am J Ophthalmol. 2008;146: 496-500.

20. Franken AM, Derkx FM, Schalekamp MH, Hop WC, van Rens EH, de Jong PT. Association of high plasma prorenin with diabetic retinopathy. J Hypertens Suppl. 1988;6:S461-S463.

21. Funatsu H, Yamashita H, Nakamura S, et al. Vitreous levels of pigment epithelium-derived factor and vascular endothelial growth factor are related to diabetic macular edema. Ophthalmology. 2006;113: 294-301.

22. Watanabe D, Suzuma K, Suzuma I, et al. Vitreous levels of angiopoietin 2 and vascular endothelial growth factor in patients with proliferative diabetic retinopathy. Am J Ophthalmol. 2005;139:476-481.

23. Nguyen QD, Tatlipinar S, Shah SM, et al. Vascular endothelial growth factor is a critical stimulus for diabetic macular edema. Am J Ophthalmol. 2006;142:961-969.

24. Bhoola KD, Figueroa CD, Worthy K. Bioregulation of kinins: kallikreins, kininogens, and kininases. Pharmacol Rev. 1992;44:1-80.

25. Yiu G, Manjunath V, Chiu SJ, Farsiu S, Mahmoud TH. Effect of antivascular endothelial growth factor therapy on choroidal thickness in diabetic macular edema. Am J Ophthalmol. 2014;158:745-751.

26. Tsuiki E, Suzuma K, Ueki R, Maekawa Y, Kitaoka T. Enhanced depth imaging optical coherence tomography of the choroid in central retinal vein occlusion. Am J Ophthalmol. 2013;156:543-547.

27. Branchini L, Regatieri C, Adhi M, et al. Effect of intravitreous anti-vascular endothelial growth factor therapy on choroidal thickness in neovascular age-related macular degeneration using spectral-domain optical coherence tomography. JAMA Ophthalmol. 2013;13:693-694.

28. Sonoda S, Sakamoto T, Yamashita T, et al. Effect of intravitreal triamcinolone acetonide or bevacizumab on choroidal thickness in eyes with diabetic macular edema. Invest Ophthalmol Vis Sci. 2014;55: 3979-3985.

29. Nagahara M, Tamaki Y, Tomidokoro A, Araie M. In vivo measurement of blood velocity in human major retinal vessels using the laser speckle method. Invest Ophthalmol Vis Sci. 2011;52:87-92.

30. Yaoeda K, Shirakashi M, Funaki S, Funaki H, Nakatsue T, Abe H. Measurement of microcirculation in the optic nerve head by laser speckle flowgraphy and scanning laser Doppler flowmetry. Am J Ophthalmol. 2000;129:734-739. 


\section{Publish your work in this journal}

Clinical Ophthalmology is an international, peer-reviewed journal covering all subspecialties within ophthalmology. Key topics include: Optometry; Visual science; Pharmacology and drug therapy in eye diseases; Basic Sciences; Primary and Secondary eye care; Patient Safety and Quality of Care Improvements. This journal is indexed on

Submit your manuscript here: http://www.dovepress.com/clinical-ophthalmology-journal
PubMed Central and CAS, and is the official journal of The Society of Clinical Ophthalmology (SCO). The manuscript management system is completely online and includes a very quick and fair peer-review system, which is all easy to use. Visit http://www.dovepress.com/ testimonials.php to read real quotes from published authors. 